\title{
A rare case of dicephalous dibrachius dipus conjoined twins: case report
}

\author{
Medha Davile, Mrunal Gaikwad*
}

Department of Obstetrics and Gynecology, Government Medical College, Nagpur, Maharashtra, India

Received: 11 June 2019

Accepted: 09 July 2019

\section{*Correspondence:}

Dr. Mrunal Gaikwad,

E-mail: mrunal.pari@gmail.com

Copyright: (c) the author(s), publisher and licensee Medip Academy. This is an open-access article distributed under the terms of the Creative Commons Attribution Non-Commercial License, which permits unrestricted non-commercial use, distribution, and reproduction in any medium, provided the original work is properly cited.

\begin{abstract}
Conjoined twin is a rare complication seen in $1 \%$ of monochorionic monoamniotic twins and associated with severe morbidity and mortality. We are reporting a case of 30 years old second gravida referred to our tertiary care center at 35 weeks of gestation with ultra-sonographic diagnosis of dicephalus conjoined twin and further confirmed after caesarean delivery.
\end{abstract}

Keywords: Caesarean, Conjoined twin, Dicephalous, Monoamniotic monochorionic, Ultrasonography

\section{INTRODUCTION}

Siamese twins or double monsters have always been a subject of curiosity and mystery for the general public. The conjoined twin is one of the rare phenomena seen in $1 \%$ of monochorionic monoamniotic pregnancy and is associated with high perinatal mortality.

Early prenatal diagnosis and precise characterization of conjoined twins are essential for optimal obstetric, interventional and postnatal management as well as to reduce psychological trauma to the parents. ${ }^{1}$

\section{CASE REPORT}

Patients with 30 years G2P1L1 with 35 weeks of gestation with previous LSCS with spontaneous conception came with complaints of preterm premature rupture of membranes since 8 hours, referred for fetal MRI admitted in GMCH Nagpur, booked at PHC Mangaon at $4^{\text {th }}$ month of gestation.
Registered at Sewagram Wardha at $6^{\text {th }}$ month of gestation, diagnosed at 35 weeks of gestation as conjoined twin. No h/o twinning in family. Ultrasonography report done at GMCH Nagpur suggestive of live intrauterine fetus of mean gestation age 33 weeks 1 day with 2 heads (BPD1 corresponds to 32 weeks and BPD2 corresponds to 34 weeks 2 days) and single body, 2 separate vertebral columns, abdomen and thorax are fused. We informed and counselled the parents regarding the nature of congenital malformation and the poor prognosis of baby and need for caesarean section. Emergency LSCS was done, dicephalous dibrachius dipus conjoint twin male baby weighing $2.6 \mathrm{~kg}$ delivered, cried weakly at birth, APGAR-6, shifted to NICU.

Intra-op: liqour-less than adequate, placenta posterior, 3 vessel cord seen, single male genitalia.

NICU course of baby- Babies kept on O2 by CPAP, ultrasonography suggestive of right dysplastic kidney. 
Babies died on day 3 of life, cause of death-day 3 male preterm with respiratory distress with respiratory failure with cardiorespiratory arrest.

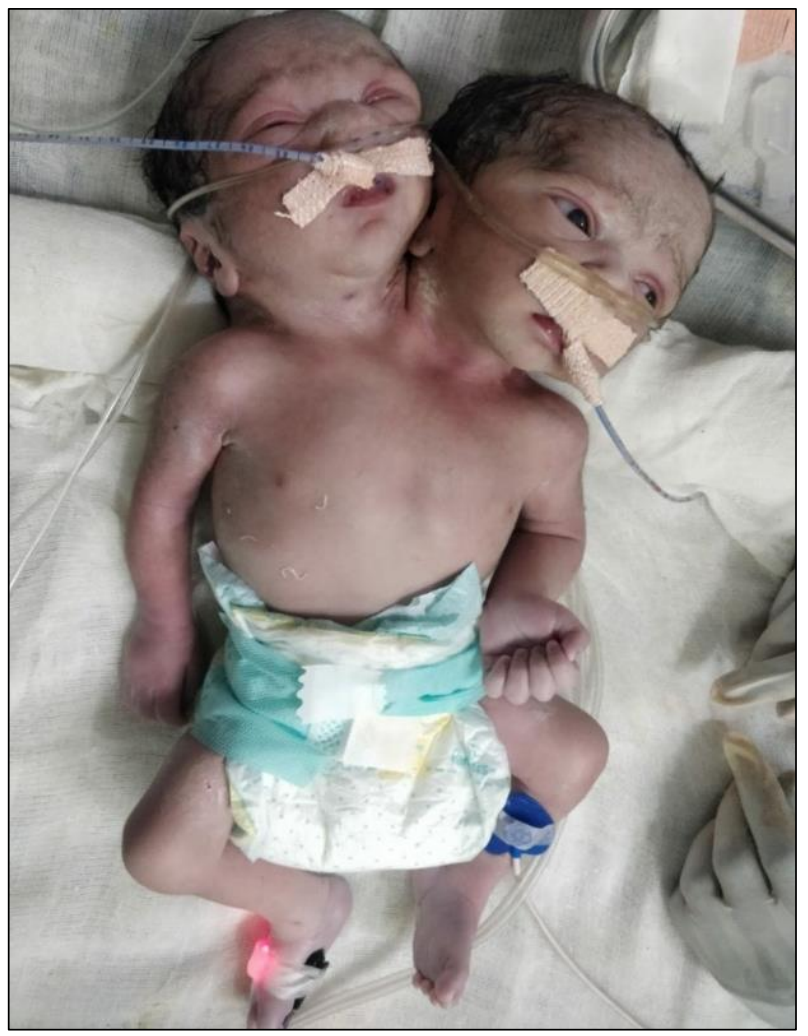

Figure 1: Newborn having 2 heads, 1 trunk, single male genitalia, 2 upper limbs and 2 lower limbs.

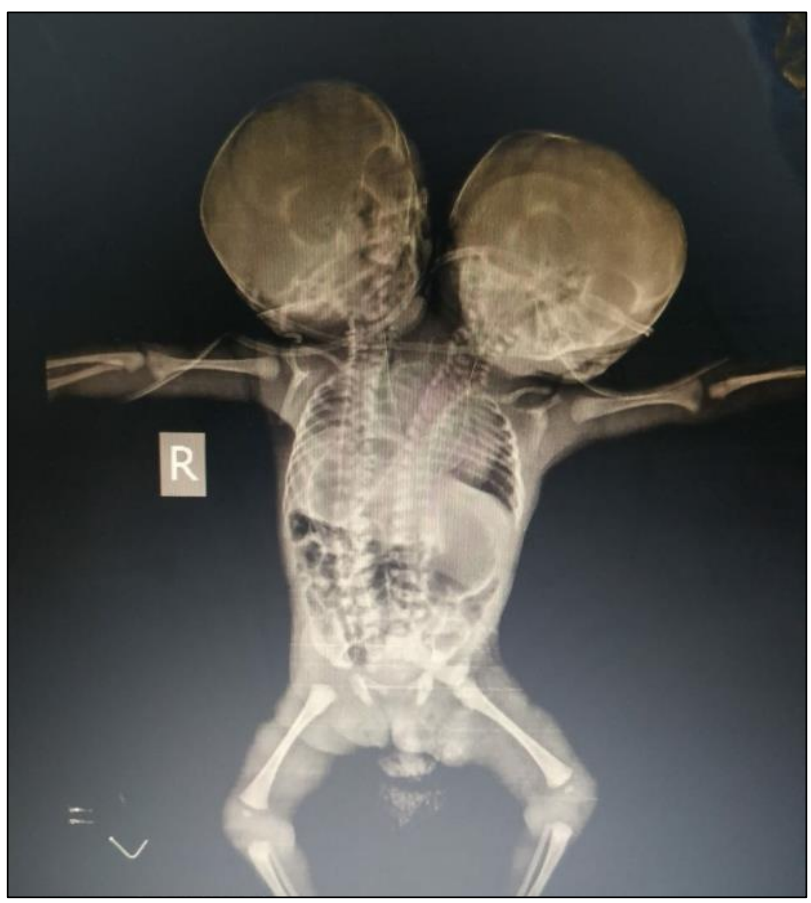

Figure 2: X-ray of baby of 2 heads, 2 spine, 2 upper limbs, 2 lower limbs.

\section{DISCUSSION}

This is a very rare condition and accounts for $1-2 \%$ of monozygotic twins. The embryonic disk starts to differentiate on the $13^{\text {th }}$ day. If the split occurs after day 13 , then the twins will share body parts in addition to sharing their chorion and amnion.

Dicephalus twins are very rare form of conjoined twins. They have two separate heads or heads fused with each other with one body. They encompass around $11 \%$ of conjoined twins and there is a female preponderance. They are subdivided into many groups depending upon the number of upper limbs, lower limbs and number of torso. Accordingly they are dicephalus tetrabrachius dipus, dicephalus tribrachius dipus and dicephalus dibrachius dipus. Most of the dicephalic twins are either still-born or succumb to neonatal death. As in any other form of conjoined twins they share vital organs and mortality is very high.

Regardless of the site of union, variations occur with regard to the internal organs. Certain organs may be common to both twins or these may be separate. . Prognosis, obstetric management and treatment planning are determined by degree of fusion and extent of joining of fetal organs. Cesarean section is recommended in most third-trimester deliveries because of the high incidence of dystocia and resultant fetal damage. ${ }^{2}$ Antenatal diagnosis by ultrasound is possible in modern day obstetrics. Ultrasonographic identification of any of the following classical signs may suggest the diagnosis: both fetal heads in the same plane, unusual backward flexion of the cervical spine, no change in the relative position after maternal movement and manual manipulations and inability to separate fetal bodies after careful observation. $^{3}$

Dicephalus dipus conjoined twins form a rare variant of conjoined twins. Such variants are usually stillborn or die immediately after birth. Separation of conjoined twins is complicated procedure. The importance of multidiscipline team with rehearsal of all aspects (surgical, anesthetic and nursing) of the operative procedure cannot be overemphasized. Although the outcome is influenced by careful planning and organization from all participants, the prognosis is often predetermined by the underlying anatomy which may preclude successful separation. ${ }^{4}$ One of the famous conjoined pair named Chang and Eng Bunker lived unseparated for 63 years; they married to two sisters and had 21 children. Literature reveals that in one of the study of 14 cases of prenatally diagnosed conjoint twins, $28 \%$ died in utero, $54 \%$ immediately after birth, and only $18 \%$ survived out of which $50 \%$ died postoperatively. ${ }^{5}$

\section{CONCLUSION}

Early and accurate diagnosis is important in conjoined twins so that parents can be counselled for options of 
termination of pregnancy. Ultrasound imaging and antenatal magnetic resonance imaging are useful diagnostic tools in early pregnancy. Two-dimensional ultrasound can demonstrate conjoined twins as early as 12 weeks of gestation Three-dimensional scan is superior to two-dimensional scan as it detects anomalies more precisely, than and as early as nine weeks of gestation.

Funding: No funding sources

Conflict of interest: None declared

Ethical approval: Not required

\section{REFERENCES}

1. Mishra N, Rohilla M. Thoraco-omphalopagus conjoint twin: a case report and literature review. Gynecol Obstet Case Report. 2015;1(1):1-4.

2. Tandon R, Sterns LP, Edwards JE. Thoracopagus twins. Arch Pathol. 1974;98:248-51.
3. Kalchbrenner M, Weiner S, Templeton J, Losure TA. Prenatal ultrasound diagnosis of thoracophagus conjoined twins. J Clin Ultrasound. 1987;15:59-63.

4. Golladay ES, Williams GD, Seibert JJ, Dungan WT, Shenefelt R. Dicephalus dipus conjoined twins: a surgical separation and review of previously reported cases. J Pediatric Surg. 1982;17(3):259-64.

5. Gothwal M, Sharma C, Yadav G A, Singh P. Raikar S. International Dicephalus parapagus conjoined twin: a rare case with review of literature. Int J Reprod Contracept Obstet Gynecol. 2018;7(8):34102.

Cite this article as: Davile M, Gaikwad M. A rare case of dicephalous dibrachius dipus conjoined twins: case report. Int J Reprod Contracept Obstet Gynecol 2019;8:3422-4. 